\title{
Erratum to: Examining Walkability and Social Capital as Indicators of Quality of Life at the Municipal and Neighborhood Scales
}

\author{
Shannon H. Rogers • John M. Halstead • \\ Kevin H. Gardner • Cynthia H. Carlson
}

Published online: 30 March 2011

(C) Springer Science+Business Media B.V./

The International Society for Quality-of-Life Studies (ISQOLS) 2011

\section{Erratum to: Applied Research in Quality of Life DOI 10.1007/s11482-010-9132-4}

The following paragraph should appear toward the end part of the Introduction section of the published article.

In particular, the approach detailed in Leyden (2003) provided a solid foundation for this work to build upon when examining the connection between social capital and built environment. Assessing walkability is a challenging task and Leyden's work offers a simplified way to determine perceived walkability by asking individuals directly about the locations they can travel to on foot from their homes. Since the submission of this article, Leyden has formally named this approach and assessed its reliability (Bias et al., 2010). As will be described, this research asked individuals about their perceptions about how conducive to destination walking their neighborhood is in a manner similar to Leyden (2003).

The online version of the original article can be found at http://dx.doi.org/10.1007/s11482-010-9132-4.

S. H. Rogers $(\bowtie) \cdot$ C. H. Carlson

Natural Resources and Earth Systems Science Program, University of New Hampshire, Durham, NH, USA

e-mail: shrogers@unh.edu

S. H. Rogers $\cdot$ K. H. Gardner • C. H. Carlson

Environmental Research Group, University of New Hampshire, Durham, NH, USA

J. M. Halstead

Department of Natural Resources and the Environment, University of New Hampshire, Durham, NH, USA

K. H. Gardner

Department of Civil and Environmental Engineering, University of New Hampshire, Durham, NH, USA 
This work went further by asking individuals what they "do" walk to and divided neighborhoods based on this behavior-based walkability score or index (i.e. based on people's reported behavior) and not based on more historically- or objectively-defined neighborhood types.

The following reference should also be added to the References section of the article.

Bias, T.K, Leyden, K. M, Abildso, C. G, Reger-Nash, B., \& Bauman, A. (2010) The importance of being parsimonious: Reliability of a brief community walkability assessment instrument. Health \& Place, 16(4), 755-758. 